\title{
Mapas y narrativas de desplazamiento. Memorias mapuche-tehuelche sobre el sometimiento estatal en Norpatagonia
}

\author{
Displacement Maps and Narratives. Mapuche-Tehuelche Memories \\ about State Subjection in North Patagonia
}

\author{
Ana Ramos* \\ Walter Delrio**
}

RESUMEN

La memoria social de las comunidades mapuche y tehuelche de la Patagonia argentina posibilita acceder a modos no hegemónicos de territorialidad que discuten, tensionan y se relacionan con la cartografía oficial. Las narraciones sobre el pasado, especialmente aquellas que refieren a las experiencias de persecución y sometimiento estatal de la generación de los "abuelos", constituyen no solo una versión desde el presente sobre aquellos procesos ocurridos en las décadas de 1870 a 1890, sino que reponen marcos de interpretación en contextos de desplazamiento. Estas constituyen un elemento fundamental tanto para la reconstrucción historiográfica de dichos procesos como también para el reconocimiento actual de diferentes modos de construcción y relación social con el espacio.

PALABRAS ClaVES: Territorialdiad. Patagônia. Memorias Mapuche-Tehuelche. Geografía de acciones

\section{ABSTRACT}

Mapuche and Tehuelche social memory allows us to access to non-hegemonic territorialization concepts that discuss official cartographies. The narratives about grand parents' suffering during the state subjection along 1870-1890 represent not only a present indigenous version on those events but it also restores interpretation frames in displacement contexts. These memories are fundamental elements for both: a historical reconstruction of subjection processes and the present recognition of different kind of relationships between social groups and space.

KEYWORDS: Territoriality. Patagonia. Mapuche-Tehuelche memories. Geography of actions.

“Allí donde el mapa corta, el relato atraviesa" (De Certeau 2000: 140).

\footnotetext{
* Investigadora del Consejo Nacional de Ivestigaciones Científicas y Tecnològicas CONICET, Profesora de la Universidad Nacional de Río Negro. Licenciada en Cs. Antropológicas por la Universidad de Buenos Aires (UBA), Magister en Análisis del Discurso (UBA) y Doctora en Antropología (UBA). Es autora del libro "Los Pliegues del Linaje. Memorias mapuche y tehuelche en contextos de desplazamiento" EUDEBA, 2010. Dirige actualmente el proyecto de investigación"Procesos de recordar y olvidar en contextos de subordinación. Una aproximación comparativa en torno a la memoria como objeto de reflexión" de la Agencia Nacional de Promoción Científica y Tecnológica

** Investigador del Consejo Nacional de Ivestigaciones Científicas y Tecnològicas CONICET, Profesor de la Universidad Nacional de Río Negro. Licenciado en Historia por la Antropológicas por la Universidad de Buenos Aires (UBA), Magíster en Etnohistoria por la Universidad de Chile, Doctor en Antropología (UBA). Es autor del libro "Memorias de expropiación. Sometimiento e incorporación indígena en la Patagonia 1872-1943", Ed. Universidad de Quilmes, Bernal, 2005.
} 
Desde ya hace muchos años que un "error" en un mapa histórico vuelve a generarnos preguntas de distinto tipo. En breve se trata del croquis que acompaña al informe oficial del Sargento Mayor Mariano Bejarano de su viaje desde Carmen de Patagones hasta "el país denominado Las Manzanas" en los meses de junio a septiembre de 1872. En este croquis se nombra como "Cerro de Villa Rica" a uno ubicado en las nacientes del río Malleo y sobre el cordón principal de los Andes, es decir en la localización exacta del Volcán Lanin. Por otra parte, la precisión geográfica que mayormente caracteriza al conjunto del croquis, se pierde al representar el "País de las Manzanas". Especialmente la orientación de los ríos cordilleranos que van de oeste a este aparece cambiada a una dirección sur-norte.

En algún momento, nos hemos detenido en este "error" del croquis discutiendo la posibilidad de que Bejarano nunca llegara tan lejos como señala su itinerario y que esto se expresara en el modo en que volcó la información brindada por sus anfitriones en su mapa. Siendo que su misión consistía tanto en observar el cumplimiento de las raciones establecidas por los tratados signados entre los caciques manzaneros Sayhueque y Ñancucheo y el presidente Sarmiento como también establecer el número de lanzas que estos pudieran reunir dado el caso, es que el Sargento Mayor procura consignar el sitio de establecimiento de estas parcialidades, sus lugares de aprovisionamiento y reunión en parlamento. El área a ser inspeccionada y representada debería ser hasta el cordón principal de los Andes, es decir el territorio reclamado para la soberanía del estado nacional argentino en esas latitudes y aún controlado por los pueblos originarios hasta las campañas de conquista estatal de 18811885-. Hipotéticamente podría sostenerse que el militar incluye dentro del ya por entonces pensado como "territorio argentino" el territorio practicado y socialmente afectivo con el cual sus interlocutores se identifican y le refieren. Así el volcán Villarica, en efecto uno de los lugares de origen de los linajes manzaneros y varios kilómetros hacia el oeste del cordón principal de los Andes, era representado como parte del territorio del País de las Manzanas, considerado por Bejarano como inminente jurisdicción argentina.

En el presente trabajo nos detendremos en los modos diferentes de pensar el espacio - evidenciados por la cartografía oficial y la memoria social- en el contexto del sometimiento estatal de la población originaria del norte de la Patagonia entre estos primeros años de la década de 1870 y los últimos de la de 1890. Habiendo recortando este periodo desde las experiencias transmitidas por la memoria social de estas comunidades hasta el presente, nos interesa: en primer lugar, preguntarnos por los modos en que esta memoria puede ser parte fundamental del trabajo historiográfico en 
la medida que da cuenta de procesos históricos como el sometimiento estatal de fines del siglo XIX. En segundo lugar, contraponer y relacionar los modos en que dichas construcciones de territorialización alternativas -como marcos de interpretación histórica y del espacio social contrapuestos- intervienen y se relacionan, con el objeto de abordar la relación entre memoria y espacio en un contexto de sometimiento estatal y desplazamiento. Quizás para permitirnos también un nuevo intento de explicación del mencionado "error" cartográfico o para reorientar nuestras preguntas.

Las narrativas mapuche-tehuelche, sobre las experiencias de persecución durante las campañas militares y el "regreso" de los abuelos, a las que haremos referencia en este trabajo son precisamente las de las familias involucrados en los desplazamientos forzados desde aquel "País de las Manzanas" de fines del siglo XIX hasta el espacio de las actuales comunidades en tierras fiscales, de colonia o reserva fiscal en la provincia de Chubut. En el presente muchas de estas familias y comunidades se encuentran en litigio por las tierras que actualmente ocupan. En mayor medida, el argumento utilizado por la contraparte en estos casos judicializados - como ha venido siendo el argumento legitimador de diferentes medidas de expropiación en el último siglo- hace hincapié en la supuesta "no originalidad" de estas familias indígenas por el hecho de considerarlas, en tanto mapuches, como provenientes del territorio de otro estado nacional o en tanto manzaneros, como provenientes de otros estados provinciales. En otras palabras, argumentando que si el lugar de origen mítico de estas familias es un lugar como el volcán Villarica, éste, en la cartografía oficial, ha quedado definitivamente del otro lado de la frontera binacional.

\section{La Relación Pasado/Presente en las Reconstrucciones de Territorialidad}

Los autores que han planteado que la historia se escribe en el paisaje, han subrayado el hecho de que el paisaje no sólo evoca memoria sino que también la produce, siendo en sí mismo memoria (RAPPAPORT, 1989; SANTOS GRANERO, 1998). Trabajando la relación entre los procesos de memoria y sus inscripciones en el espacio físico ellos retoman una de las discusiones centrales que, en los últimos años, ha estructurado el campo de los estudios sobre memoria. Ésta es la que se ha planteado entre las posturas teóricas que subrayan los condicionamientos del presente sobre las construcciones y usos del pasado, y aquellas otras que, centradas en la reconstrucción del pasado, subrayan la autonomía de éste en relación con el presente. Del mismo modo, cuando las representaciones sobre la territorialidad indígena son objeto de los 
procesos de recordar y olvidar, los autores suelen posicionarse en alguna de esta dos tendencias teóricas: en los usos estratégicos de estas representaciones para los fines pragmáticos del presente (específicamente los conflictos actuales por la tierra) o en los conocimientos constitutivos de una ontología indígena sobre el territorio que es transmitida de generación en generación con autonomía de las circunstancias presentes. Nuestro propósito es enmarcar el trabajo entre estas dos perspectivas para explicar por qué las representaciones sobre la territorialidad son parte de los procesos de lucha del presente como pueden también ser fuente de acceso a otros modos de conciencia histórica e interpretación del pasado.

En primer lugar, siguiendo las lecturas de Walter Benjamin realizadas por J ohn McCole (1993), consideramos que el potencial político de las representaciones sobre territorialidad no reside tanto en las definiciones y usos que las personas indígenas esgrimen para fines concretos, sobre todo cuando los criterios de legitimidad son impuestos por las leyes y las burocracias estatales. Más bien, y como lo hace este autor, ubicamos la fuerza política de la memoria sobre el territorio en un momento preciso de articulación entre pasado y presente. Aquel en el cual, las trayectorias sociales de los grupos y las personas, y los contextos de lucha del presente, iluminan de un modo particular ciertas imágenes del pasado, retransmitidas generacionalmente, precisas, y parcialmente autónomas. En determinados contextos, imágenes aparentemente dispersas - transmitidas en cuentos, cantos sagrados, partes de rituales, nombres de lugares, relatos históricos-- operan como índices de nuevas conexiones y asociaciones con otras imágenes del pasado y del presente. Por lo tanto, la política no es aquí una invención de la memoria sino una reconexión contextual de imágenes heredadas, es el momento preciso de la articulación entre pasado y presente en el que las imágenes del pasado se reconectan y articulan en un marco de intepretación histórico culturalmente significativo para las coyunturas del presente.

Así, por ejemplo, en el caso de los resguardos (comunidades) analizados por J oanne Rappaport (1989, p. 85), los sitios sagrados de los Páez (Colombia), dispersos a través del área, sirven tanto como claves mnemónicas sobre la historia y como marcadores de límites para los mismos resguardos. Entonces, estas historias espacializadas tanto reconstruyen eventos del pasado como enraizan las instituciones indígenas en una concepción local de territorio, pudiendo servir, en ocasiones, a los objetivos pragmáticos de recordar los límites políticos y legitimar la defensa del territorio. Sin embargo, muchos de los recuerdos espacializados de los grupos mapuche y tehuelche tienen una relación más compleja con estos intereses inmediatos. Lo que ellos están expresando en primer lugar es que los marcos oficiales sobre la delimitación 
del espacio son restringidos, atemporales y miniaturizados. Estas historias no hablan de mojones y límites sino de movilidades, relaciones sociales y conexiones entre lugares. Esto es, de concentraciones, deportaciones, separación de grupos y expropiaciones sistemáticas que a lo largo del tiempo han enmarcado las relaciones entre la población originaria y el estado.

En segundo lugar, no se trata tampoco de reflejar en un mapa alternativo la distribución previa -a la realización de las campañas militares de conquista estatal- a través de los mitos. Más bien, y siguiendo a J onathan Hill (1993), estas narrativas no congelan la historia en un orden mítico, sino que incorporan la experiencia de la dominación. En este sentido, las representaciones de territorialidad conectan imágenes en el marco histórico más amplio del movimiento, específicamente, de los desplazamientos impuestos por los estados nacionales. Es precisamente en este desplazamiento donde se producen los marcos de interpretación en los que se funda un tipo de conciencia histórica sobre el pasado y sobre el territorio. Los estudios sobre ontologías indígenas suelen reconstruir cartografías atemporales, absolutamente "otras" y homogéneas. Sin embargo, estas cartografías heredadas del pasado no son visiones del mundo atemporales sino resultantes de procesos históricos específicos. En el caso de los grupos mapuche y tehuelche, y como hemos dicho anteriormente, han sido los momentos de crisis - persecuciones de los ejércitos, traslados de personas, campos de concentración y pérdida de seres queridos-los que modalizaron y produjeron las conexiones entre eventos que hoy perduran como memorias sobre el territorio.

Estos modos de ver y estar en el mundo - de habitar y sentir el entorno-han ido cambiando, entonces, a través del tiempo y de formas diferentes según las experiencias de los grupos, familias y personas. Los marcos de pensamiento, conocimientos y valores sobre el pasado no siempre han sido los mismos y tampoco han focalizado siempre en los mismos acontecimientos. Sin embargo, pensadas como reconstrucciones de las experiencias pasadas y presentes, todas estas ontologías han sido igualmente verdaderas. Desde este ángulo y en el marco de los estudios sobre aboriginalidad, distintos autores (RUMSEY, 2001) han caracterizado el contexto presente como un momento político de articulación con el pasado en el que la territorialidad es puesta en un primer plano. En un sentido amplio, para Henri Lefebvre (1976), este énfasis es el resultado de una coyuntura histórica particular del capitalismo, puesto que en el espacio y por el espacio se reproducen las relaciones de producción: 
El espacio ha sido siempre político pero ahora lo es más que nunca. En el espacio planetario, en el espacio de la tierra, se enfrentan las estrategias y en lo concerniente a la estrategia todo es un asunto de espacio. Los recursos puestos en marcha, los objetivos estratégicos, las ideologías y los elementos teóricos (LEFEBVRE, 1976, p. 222)

Específicamente para quienes trabajan las representaciones indígenas de territorialidad, este énfasis surge cuando la desposesión de la tierra aborigen resultó completa. En este contexto y para el caso australiano, Rumsey (2001) sostiene que la objetivación de la identidad social en el paisaje ha tomado una nueva fuerza, en tanto no sólo provee a los pueblos aborígenes bases reconocibles para los reclamos de áreas determinadas de tierras sino que también deviene parte de lo que significa ser una persona aborigen en Australia.

En pocas palabras, el presente - en tanto contexto de iluminación sobre los eventos del pasado-es el que conecta las imágenes heredadas, los fragmentos de experiencias pasadas y determinadas narrativas poéticas con centro en el espacio como el escenario de las disputas. Pero estas imágenes, fragmentos y narrativas han sido transmitidos de generación en generación, incluso cuando sus sentidos no siempre hayan sido igualmente conectados y comprendidos. Esta autonomía parcial es, según entendemos, la fuerza política de la tradición en la que algunos autores han hecho hincapié (KOHN, 2002).

\section{Modelos de Territorialidad}

El modelo hegemónico de territorialidad es el que, por ejemplo, solemos actualizar los investigadores cuando, participando como peritos o como testigos en una instancia judicial, emprendemos la empresa de buscar evidencia y datos de ocupación tradicional indígena en las tierras específicas que se encuentran en conflicto. En esta dirección, la tarea suele consistir en reconstruir la historia en la que las taperas, los cementerios comunitarios, u alguna otra marca física devienen en la prueba de que abuelos y abuelas (de tercera o cuarta generación ascendente) del supuesto "usurpador" habían vivido en esos lotes que hoy se encuentran en conflicto. Asimismo, estas evidencias suelen necesitar también un complemento documental que permita probar una relación sanguínea (o filiación reconocida en actas de nacimiento, casamiento o defunción) entre unos y otros. Aun cuando con estos procedimientos no siempre está asegurado el éxito del conflicto a favor de los indígenas, en los casos en que esta reconstrucción es posible, solemos pensar, al menos, que debería serlo. 
Sin embargo, está lejos de ser éste el caso más generalizable. Tal como hemos mencionado anteriormente, la historia de los grupos parentales indígenas ha sido otra. Por eso creemos que una discusión sobre territorialidad exige la incorporación de otros modelos y marcos de interpretación sobre el espacio que nos permitan pensar la continuidad de un grupo en un mismo territorio pero también las formas alternativas de practicar la territorialidad en contextos impuestos de desplazamiento. El trabajo con las memorias es un camino fructífero para repensar los supuestos sobre los que estamos discutiendo la legitimidad de personas o familias en un lote específico de tierra.

Al circunscribir la discusión al criterio de la continuidad en un mismo lugar estamos presuponiendo, por un lado, la existencia de determinados límites - y una forma particular y restringida de comprender la territorialidad como un tipo de "propiedad"- y por el otro, una noción de parentesco basada en relaciones de consanguineidad. En palabras de Alexis Papazian, estaríamos confirmando una construcción particular de mapas-calco:

\begin{abstract}
Siguiendo algunas líneas de pensamiento deleuziano, notamos que las definiciones hegemónicas suelen generar puntos estáticos de repetición y reproducción, es decir calcos estructurados por la cienciaverdad, pero articulados y amplificados por meta-instituciones (con carga política) [...] Es así que 'el calco ha organizado, estabilizado, neutralizado las multiplicidades según sus propios ejes de significación [...] y cuando cree reproducir otra cosa ya solo se reproduce a sí mismo. Por eso es tan peligroso, inyecta redundancias y las propaga.' (DELEUZE; GUATTARI, 1997, p. 18-19 apud PAPAZIAN 2008, p. 6).
\end{abstract}

Desde este ángulo, consideramos que el espacio sobre el que suele pensarse la noción de territorialidad es uno ya fragmentado, "pulverizado por la propiedad privada" y en el cual "cada fragmento del espacio tiene su propietario" (LEFEBVRE, 1976, p. 224). Así entendidos, los lugares demarcados en este espacio constituyen una configuración de posiciones y relaciones de coexistencia e implican una indicación de estabilidad (DE CERTEAU, 2000).

Sin embargo, estas operaciones de deslinde sobre el espacio también son contratos narrativos sobre cómo contar la historia. La descripción del espacio, incluyendo los mapas hegemónicos, es más que un acto de fijación, es, sobre todo, un acto histórico y cultural con fuerza performativa y poder distributivo. El mapa autoriza o desautoriza los establecimientos, los desplazamientos y los rebases de límites. En un mapa están presentes las historias que los fundan, las matrices de inclusión y exclusión, y las combinaciones jurídicas que lo confirman, aun cuando éste tenga el efecto de la 
neutralidad y verosimilitud sobre aquello que representa. Sin embargo, no todas las historias fundan o están presentes en todos los mapas.

A continuación, entonces, nos centraremos en aquellas representaciones de territorialidad que cuestionan las nociones estáticas del espacio, sus mojones y sus límites para introducir el afecto y el apego hacia el territorio en un proceso histórico más amplio y de múltiples trayectorias de movimiento.

\section{Memorias en y de Contextos de Desplazamientos Impuestos: Geografías de Acciones}

Distintos autores han comenzado a hablar de relatos de viaje (DE CERTEAU, 2000), caminos de poder (ABERCROMBIE, 1998) o narrativas de marcha (RUMSEY, 2001) para describir el espacio físico y social. En esta misma línea, pero haciendo hincapié en el proceso particular de sometimiento estatal de los pueblos mapuche y tehuelche, hablamos aquí de "memorias en contextos impuestos de desplazamiento".

Estas narrativas son evocadas por las personas mapuches y tehuelches en situaciones formales y rituales - como por ejemplo la realización del camaruco (ceremonia religiosa) - e informales y cotidianos - como puede ser una conversación. Incluimos en las memorias del desplazamiento narrativas que pueden corresponder a distintos periodos históricos entre las décadas de 1870 y 1890. Algunas son contextualizadas en los años en que los grupos huían de los ejércitos nacionales argentino y chileno- y otras remiten a los años de los campos de concentración, cuando los protagonistas de los relatos - generalmente mujeres-lograban escapar de allí o cuando, hacia fines de los '90, éstos fueron levantados (después de aproximadamente diez años de funcionamiento).

Estos dos conjuntos de historias que aquí hemos seleccionado orientan el argumento de este trabajo en dos direcciones diferentes. Las primeras discuten los límites en los que suelen circunscribirse a los grupos étnicos de la Patagonia Argentina al momento en que se efectúan las campañas militares. Las segundas, en cambio, subrayan el contexto en el que comienzan a delimitarse los mapas calco como fragmentos de propiedad privada (en el sentido de Lefebvre, 1976). Esta última, en efecto, se impone tempranamente en Norpatagonia y se constituirá hegemónicamente como el único tipo de vinculación con el espacio oficialmente legitimada. El marco común de interpretación de estos dos conjuntos de narrativas es su foco en la reestructuración permanente de las relaciones sociales y en una concepción de 
territorialidad que por el contrario está centrada en la movilidad como criterio de pertenencia y apego a los lugares.

El concepto de "geografía de acciones", acuñado por De Certeau (2000), nos permite entender la representación histórica de estos recorridos como espacios practicados, con sus vectores de dirección, cantidades de velocidad y variables del tiempo. Así entendido, el espacio es el resultado histórico de un cruzamiento de movilidades, de las operaciones que lo orientan y lo circunstancian. Las montañas, los ríos, los mallines, las pampas o los trazos de caminos definidos como demarcadores de límites étnicos o de propiedades privadas en estos mapas se transforman en el espacio de una territorialidad específica por la intervención de quienes los caminaron, cruzaron o acamparon.

Las primeras geografías de acciones que hemos seleccionado aquí son las narrativas que reconstruyen diferencialmente los grupos parentales para explicarse a sí mismos las relaciones sociales de su pertenencia compartida. La gente denominada como "los Tramaleo", "los Nahuelquir", "Ios Sayhueque" o "los Nahuelpan" pueden contar la historia sobre el "estar juntos" desde la fundación de la comunidad actual en la tierras de su relocalización post-sometimiento (ya sea en tierras de reserva fiscal o en colonias agrícolas y pastoriles). Pero en ocasiones los narradores optan por transformar estos relatos fundacionales en fragmentos o eslabones de una historia de más larga duración. En estas últimas nos detendremos ahora.

Contar la historia desde el punto de vista de un nombre particular, por ejemplo "los Nahuelquir", implica una selección de eventos centrados en las acciones de determinados ancestros pero sin incurrir en una historia de parientes en sentido estricto. La periodización de los eventos suele tomar como referencia el nombre de algunos caciques, o ciertos acontecimientos específicos. La época en que "todos estaban juntos y mezclados" refiere a los tiempos pre-conquista en que "manzaneros, mapuches y tehuelches formaban pueblitos", una época de relacionalidad basada en las alianzas, afinidades, enemistades y conflictos entre grupos parentales. Grupos de parientes que no se definían exclusivamente por consanguineidad, puesto que las relaciones de crianza, lakutun (crear relación parental a través de la acción de "dar el nombre"), alianza, matrimonio, cercanía geográfica, eran parte de los patrones de "familiarización". Los ancestros de quienes hoy se reconocen como el grupo de "los Nahuelquir", formaban parte de otros grupos y relaciones que los narradores suelen nombrar con la expresión amplia de "manzaneros" - aquellos relacionados con quienes vivían en el País de las Manzanas (DELRIO, 2007). El espacio practicado en estos años era uno amplio y de múltiples cruces. Hacia el oeste, las relaciones de una pertenencia 
común se extendían hacia el otro lado de la cordillera de Los Andes. Hacia el sur, sabemos que alguien dirigiéndose hacia el norte ya en las proximidades de la actual ciudad de Tecka (provincia del Chubut) se detenía para anunciar su visita a alguno de los grupos parentales denominados como "los manzaneros" (MUSTERS, 1991). Hacia el norte sabemos que más allá del volcán Lanín, se seguían encontrando tolderías que podían reconocerse a sí mismas como formando parte de este mismo grupo (MORENO, 1876). La memoria social sobre estos años subraya la heterogeneidad, la toma de decisiones conjuntas, las estrategias político-militares de los caciques y el contexto histórico de estas alianzas y relaciones.

La memoria oral, no obstante, incorpora mayor cantidad de detalles, nombres y especificaciones espaciales cuando, ya iniciadas las campañas militares hacia el año 1881, el ejército argentino llega a esta región y los grupos que la habitaban inician distintos derroteros. Uno de estos grupos se dirige hacia el Oeste, cruzando la cordillera a través de una región a la que se recuerda como "Trankura Mapu". Allí el grupo acampa varios meses, entre las montañas. Se seguían haciendo parlamentos y reuniones para pensar estrategias conjuntas entre los distintos grupos parentales. Para este tiempo, el hijo de Fernando Nahuelquir, llamado Miguel Ñancuche, comienza a destacarse entre otros jóvenes líderes. En la cordillera, en algún lugar cercano al volcán Villarrica, el grupo de Fermando y Miguel ve en la cima de una montaña a un conjunto de personas haciendo una ronda (la ronda de la ceremonia del camaruco). Estas personas eran ancestros muy antiguos. Fernando ya había tenido noticias a través de sus sueños que él iba a heredar un camaruco para su gente. Allí, en el medio de la cordillera, y en tiempos de las campañas militares, los Nahuelquir reciben los conocimientos para realizar un camaruco propio y, con esta herencia, se conforma el grupo que hoy se reconoce como "los Nahuelquir". En esos tiempos, y también en algún lugar de la cordillera, la machi del grupo que intermediaba entre los ancestros y las personas vivas, anunció que el hijo de Fernando Nahuelquir, Miguel Ñancuche, sería cacique y guiaría a su gente hacia algún lugar para poder estar tranquilos.

Finalmente, luego de su presentación a las tropas argentinas, fueron tomados prisioneros en el campo de concentración de Chinchinales, donde Miguel Ñancuche ya era cacique de un grupo, tal como lo era Sayhueque y con quien compartía el mismo sitio de reclusión. En la memoria oral, la historia cronológica se sigue contando a través de otro tipo de narrativas poéticas en las que nos detendremos después. Al levantarse los campos - algunas personas que hoy conforman el grupo de los Nahuelquir han estado alrededor de 10 años prisioneros allí--, este grupo inicia el regreso hacia tierras alambradas y privatizadas. Finalmente llegan al paraje del arroyo Cushamen donde 
obtendrán, luego de una serie de negociaciones y viajes a Buenos Aires, un otorgamiento de las tierras como Colonia Agrícola y Pastoril por parte de un decreto del presidente Julio Roca con fecha del 5 de julio de 1899. Una vez allí establecidos, ellos recuerdan que sus animales comienzan a morir, que las tierras resultaban inhóspitas y que muchos seres queridos también fallecían. El grupo resolvió entonces que una pequeña delegación regresara hasta el Villarrica - ahora en territorio considerado como parte del estado nacional chileno-, para pedirle a los ancestros que yacían en aquel volcán permiso para constituir un nuevo rewe (altar de camaruco) en las tierras de Cushamen recientemente obtenidas a cientos de kilómetros hacia el sur -y en el ahora considerado territorio de otro estado nacional. Después de realizado el protocolo ritual de traslado del rewe, el camaruco se levantó todos los años en este nuevo espacio.

Antes de la herencia del camaruco de los Nahuelquir, las familias que allí se encontraban juntas formaban parte de distintos grupos de pertenencia así como, hoy en día, otras comunidades y camarucos también se fueron desprendiendo de este grupo denominado como los Nahuelquir. La memoria subraya el movimiento del grupo y la refundación de las pertenencias para hablar de las relaciones tanto de las relaciones históricas como de las presentes. Al momento en que llegan a Cushamen, el grupo de los Nahuelquir se conformaba por algunas familias con apellido Nahuelquir y por otras 22 familias con otros apellidos. El grupo se iría conformando en el recorrido. Las experiencias comunes de lucha y la búsqueda de reestructuración política y afectiva de los lazos sociales instauran un proceso de familiarización que va más allá de las relaciones de matrimonio y procreación.

Hoy en día, en el camaruco de los Nahuelquir, se mencionan las regiones de Manzana Mapu y Trankura Mapu. Actualmente, con el rewe constituido en Cushamen, cuando se canta el tahiel (canto sagrado), se espera que el viento lleve su mensaje hasta el pillán (volcán) del norte en el que se encuentran los ancestros de quienes heredaron ese camaruco.

Las segundas geografías de acciones son reconstruidas a través de las memorias del regreso. Aquellas historias que cuentan - aun cuando no lo hagan literalmente- el recorrido de ciertas personas - generalmente mujeres-, desde los campos de concentración en los que estuvieron detenidas hasta el momento en que se encuentran con un grupo al que se reconoce como parientes. De los lugares donde "los mataban a todos" hasta "el poblado" o "la casa".

Aún cuando en estas historias el énfasis también está puesto en la reestructuración de los grupos, suelen ser denominadas como "historias tristes" (la expresión "mi abuelita sabía llorar cuando contaba" devino en la fórmula que actualiza 
el sentimiento de tristeza que motivaba y motiva tanto contar como callar estos relatos). Estas historias también pasaron a la memoria como piezas de arte o como relatos poéticos con ciertas formas y estructuras similares, incluso entre personas de regiones diferentes. La extensión de estas narrativas entre las actuales provincias de Santa Cruz, Chubut, Río Negro y Neuquén, nos estaría indicando la masividad de las experiencias históricas sobre las que tratan (DELRIO, 2010). Como las hay de distinto tipo, nos limitamos aquí a describir alguno de sus puntos en común.

Generalmente el hambre, la soledad y la desesperación de las personas, resultado de haber estado en los campos de concentración, de encontrarse separadas de las personas queridas y de haber visto disgregado a sus grupos de pertenencia, se corporiza en la mujer que protagoniza el relato. En el relato de este regreso, con detalles sobre las dificultades para obtener comida, sobre el cansancio de la marcha y sobre las largas distancias recorridas, pueden aparecer otros "viajantes" (otros grupos indígenas también en regreso) o los ancestros (por ejemplo, a través del nawel - tigreo los antiguos que viven debajo de la tierra) para formar un nuevo grupo, para acompañar o para devolver conocimientos perdidos, respectivamente. Las personas van encontrándose y reconstituyendo lazos, al mismo tiempo que buscan un lugar donde vivir tranquilos. Los pocos grupos que pudieron permanecer en el lugar que se encontraban antes de las campañas, o quienes más tempranamente obtuvieron tierras para habitar con sus familias, funcionarán para estas personas en regreso como lugares de paso y, en algunos casos, como los nuevos lugares de permanencia. Este hecho es señalado tanto en las narrativas centradas en el viaje, como aquellas que describen "el regreso de la gente" desde un lugar fijo de localización (como es el caso, por ej. de "los Cual", en la localidad de Gan Gan en el norte de la meseta central del Chubut). Para algunos grupos, estos derroteros se prolongaron durante varios años, trasladándose de una a otra localidad, hasta llegar al sitio en el que se estabilizaron finalmente según las normas vigentes sobre el espacio y sus límites.

En estas geografías de acciones que las memorias actualizan - en narrativas sobre el tiempo de las "matanzas", por un lado, y sobre las experiencias "tristes", por el otro--, las personas mapuche y tehuelche utilizan una noción de territorialidad en la que se intercalan momentos de fijeza con momentos de movilidad. Retomamos aquí la discusión planteada por algunos de los autores que han trabajado esta particularidad del espacio practicado.

En primer lugar, y haciendo una lectura propia de De Certeau (2000), las memorias fijan, detienen el tiempo o construyen el "estar ahí", cuando, por ejemplo, se levanta la tumba de un ser querido que falleció en el camino, cuando en la marcha se 
entierra una olla de plata en determinado lugar (expresado como las riquezas del grupo, se trata también de las mismas tumbas que en el nuevo contexto deben permanecer secretas para evitar su profanación (DELRIO, 2007) o cuando se constituye un determinado mallín como pampa del camaruco en la cual levantar un altar (rewe), entre otros ejemplos. Pero las memorias también introducen movimiento en el espacio, por ejemplo cuando un volcán, un lago, un río o una piedra devienen el lugar de la ancestralidad, cuando un tigre guía el camino, cuando un lugar debajo de la tierra, habitado por gente antigua, puede formar parte del recorrido del viaje de regreso. En estos casos, ciertos lugares del paisaje adquieren movimiento - incluso agencia propia-- condicionando la producción del espacio y las asociaciones entre sitios e historias. Los relatos efectúan pues un trabajo que, incesantemente, transforma el movimiento en fijeza y la fijeza en movimiento. Desde este ángulo, y de acuerdo con De Certeau, las acciones realizadas en la marcha - de huida o de regreso-multiplican las geografías o espacios practicados.

En esta dirección, el mapa de la territorialidad indígena vuelve a llamarnos la atención sobre el hecho que el mapa-calco no es un orden de lugares, un cuadro, un dato científico independizado de los itinerarios que lo hicieron posible. Las representaciones de la territorialidad en las memorias mapuche y tehuelche vuelven a introducir los recorridos, las acciones espacializantes y los trazos de historias, las experiencias y marchas en los mapas que las niegan. Así como el volcán Villarica estaba muy presente en la territorialidad de quienes vivían en Las Manzanas, como para que el militar argentino lo incluyera en su croquis, situándolo al este de la frontera nacional.

En segundo lugar, la interconexión entre fijeza y movimiento en las concepciones de territorialidad fue trabajada en los estudios interdisciplinarios sobre las memorias de los grupos indígenas australianos (RUMSEY 2001; STEWART; STRATHERN, 2001). Ellos hicieron propia la pregunta efectuada por Deleuze y Guattari (1997): ¿El este, Oceanía en particular, ofrece algo así como un modelo rizomático opuesto en cada aspecto al modelo del árbol de Occidente?

Mientras el modelo arbóreo está basado en sistemas jerárquicos fijos, con centros de significación y de subjetificación, y subunidades a niveles sucesivos de ramificación, el rizomático no niega jerarquías y ramificaciones pero hace hincapié en la posibilidad permanente de reconexión. Rumsey (2001) sostiene que la noción de rizoma puede ser útil como modelo para pensar las representaciones de territorialidad que emergen de las memorias de los indígenas australianos. El territorio - para los aranda y los ngrinyin - está firmemente diferenciado y de maneras relativamente fijas y estables, pero los lugares están interconectados de maneras múltiples, atravesadas y no 
jerárquicas. En el marco de esta discusión, y también pensando sobre las representaciones de la territorialidad entre los indígenas australianos, Pamela Stewart y Andrew Strathern (2001) reflexionan sobre el interjuego entre fijeza y movilidad a partir de la memoria social de los indígenas. Haciendo referencia a las historias de marcha, estos autores encuentran que, en las memorias, ciertos sitios rituales se vinculan entre sí en el marco de trayectorias más amplias, específicamente, a través de los itinerarios de una figura ancestral y por la transferencia de un sitio a otro para llenar de nuevo la fertilidad de la tierra. Tal como dijimos antes, estas narrativas no congelan la historia en un orden mítico, sino que incorporan la experiencia de la dominación. Estos autores llaman "eventos creativos" a aquellos acontecimientos de la historia de un grupo que explican la conexión entre lugares a través de los itinerarios de un ancestro que encuentra un lugar, reconoce en éste el poder o la presencia de los ancestros, se detiene sobre él y lo nombra para su grupo (o nombra a su grupo en ese lugar). En este sentido, el grupo de los Nahuelquir, tanto en las montañas como en las tierras en las que fueron relocalizados, encontraron, reconocieron, se detuvieron y se nombraron. Los eventos creativos que pueden haber ocurrido en el transcurso de la marcha son interpretados en las memorias, también en los relatos mapuche y tehuelche, como conectados entre sí.

Las fuerzas creativas de la ancestralidad pueden volver a manifestarse a sí mismas a las personas y grupos de tiempos diferentes y en diferentes lugares. En esta dirección, y también siguiendo a los autores mencionados, no resulta incomprensible ni que un grupo reconozca dos o más lugares "creativos" de pertenencia - por ejemplo, Manzana Mapu, Trankura Mapu y Cushamen-- ni que un reclamo de tierra necesite depender obligadamente de una evidencia de conexión ancestral con el origen del grupo en un determinado lugar.

Las memorias de marcha tienen la particularidad de localizar a las personas que las transmiten y las heredan en el sitio final del recorrido, o como ocurre generalmente, definir los sitios donde se encuentran las personas que heredan las historias en el punto final de la ruta (CAÑUQUEO, 2005). En consecuencia, estos sitios actuales de ocupación - lotes, parajes, colonias o barrios-- se transforman en un lugar de apego a partir del interjuego entre movimiento y fijeza.

\section{Conclusiones}


Sin embargo, el nómade es más bien aquel que no se mueve, es el que no se va y no quiere irse. Definir al nómade por el movimiento es falso. El nomadismo es la respuesta para desafiar el movimiento. (DELEUZE; GUATTARI, 1997, p. 385)

Los testimonios indígenas recogidos por Bejarano para la construcción del croquis planteaban una distancia afectiva diferente a la métrica del mapa calco entre ciertos puntos de referencia, como aquella entre el volcán Lanin y el Villarrica. Asimismo, las narrativas mapuche y tehuelche transmitidas generacionalmente sobre aquellos años conectan lugares de pertenencia obliterando la importancia de las fronteras que actualmente los separan, como es el caso del rewe levantado en la cordillera de los Andes en las cercanías del Villarrica y el rewe levantado luego en las tierras de Cushamen (hoy provincia de Chubut). Finalmente, en la memoria social ciertos lugares físicos o seres de la naturaleza devienen agentes históricos que intervienen y orientan el curso en las historias sobre el regreso.

Nos hemos centrado en las narrativas históricas que la memoria ha seleccionado para mostrar también los sentidos que son actualizados desde un marco de interpretación alternativo sobre la territorialidad. Uno en el que el énfasis está puesto en la reestructuración de los grupos de pertenencia y de las relaciones con los lugares, desde conocimientos y saberes que se han transmitido y experimentado como propios a través del tiempo. Un marco para pensar la territorialidad cerca de los procesos históricos en los que se dirimen las cartografías hegemónicas y las geografías de acciones de los grupos mapuche y tehuelche.

En esta dirección, quisiéramos compartir algunas reflexiones de índole metodológica y teórica. En relación con las primeras, consideramos que la incorporación de la etnografía histórica como producción de información y datos resulta un procedimiento necesario para tensionar la información y los datos canónicos de las fuentes éditas y oficiales. En esta línea, creemos que la memoria social mantiene cierta autonomía del presente en las narrativas entextualizadas poética y artísticamente, y en consecuencia, son una importante fuente de acceso sobre "lo que sucedió en el pasado".

Con respecto a las reflexiones teóricas, creemos que la memoria social permite refinar categorías más generales al incluir en ellas el contexto, la historia y las experiencias desde las cuales se producen. En el caso de la noción de territorialidad utilizada en las narrativas mapuche y tehuelche, ésta parece incluir algo más que mojones, límites y fronteras espaciales. La territorialidad es el espacio social en el que 
montañas, ciertos animales, los subsuelos y los ríos, por ejemplo, introducen acciones que modifican las geografías. Asimismo, es un espacio social que se describe a partir de las distancias de la marcha recorrida y de las relaciones sociales que se fueron entramando en las distintas paradas, por lo cual hemos insistido en la puesta en primer plano de las conexiones más que en las delimitaciones entre lugares.

Finalmente, y considerando que la discusión sobre las representaciones de territorialidad en el siglo XIX es una de las arenas en las que se dirimen las disputas actuales, la memoria social vuelve a recordarnos que cualquier mapa calco es efecto de la historia tanto como lo es la representación de la memoria sobre la territorialidad. Uno de los desafíos de este debate será poder repensar los marcos jurídicos o las categorías hegemónicas de sentido común utilizadas para definir los criterios de legitimad indígena desde enfoques que vuelvan a introducir las experiencias históricas, la diversidad de pensamientos y las relaciones históricas asimétricas de poder en la construcción de las cartografías. En pocas palabras, se trataría de entender las fijezas (detenciones) en historias de más larga duración, historias que en el caso de los mapuche y tehuelche, han sido de desplazamientos continuos eimpuestos.

\section{Referências}

ABERCROMBIE, Thomas. Pathways of memory and power: ethnography and history among an Andean people. Madison: The University of Wisconsin Press, 1998.

BAYER, Osvaldo (Coord.). Historia de la crueldad argentina: J ulio A. Roca y el genocidio de los Pueblos Originarios. Buenos Aires: Ediciones del Tugurio, 2010.

CAÑUQUEO, Lorena. Los ngutram: relatos de trayectorias y pertenencias mapuches. In: CONGRESO INTERNACIONAL DE ETNOHISTORIA, 6., 2005, Buenos Aires. Anais... Buenos Aires: Facultad de Filosofía y Letras, 2005.

DE CERTEAU, Michel. Relatos de espacio. In: . La invención de lo cotidiano I: artes de hacer. México: Universidad Iberoamericana, 2000. p. 127-142.

DELEUZE, Gilles; GUATTARI, Félix. Mil mesetas: capitalismo y esquizofrenia. Valencia: Editorial Pre-Textos, 1997.

DELRIO, Walter. Del no-evento al genocídio: pueblos originarios y políticas de estado en Argentina. Eadem Utraque Europa, Buenos Aires, p. 10-11, 2010.

. El genocidio indígena y las ollas ocultas en los Andes. In: XXVII İNTĒĒTATATIONAL CONGRESS, 27., 2007, Montreal. Actas... Montreal: Latin American Studies Association, 2007. p. 10-12.

DELRIO, Walter; LENTON, Diana; MUSANTE, Marcelo; NAGY, Mariano; PAPAZIAN, Aléxis; PÉREZ, Pilar. Discussing the indigenous genocide in Argentina: past, present 
and consequences of argentinean state policies on native peoples. Genocide Studies and Prevention, Toronto, v. 5, n. 2, p. 138-159, 2010.

HILL, J onathan D. Keepers of the sacred chants: the poetics of ritual power in an Amazonian society. Tucson: University of Arizona Press, 1993.

KOHN, Eduardo. Infidels, virgins and the black-robed priest: a back woods history of ecuador's Montaña region. Ethnohistory, Columbus, v. 49, n. 3, p. 545-582, 2002.

LEFEBVRE, Henri. La producción del espacio. In: Espacio y política. Barcelona: Península, 1976. p. 219-229.

McCOLE, J ohn. Walter Benjamín and the antinomies of tradition. London: Cornell University Press, 1993.

MORENO, Francisco. Viage a la Patagonia Septentrional. In: CONGRESO CIENTÍFICO INTERNATIONAL AMERICANO, 1876, Buenos Aires. Anales... Buenos Aires: Sociedad Científica Argentina, 1876. t. 1. p. 182-197.

MUSTERS, George Chaworth. Vida entre los patagones: un año de excursiones por tierras no frecuentadas desde el Estrecho de Magallanes hasta el Río Negro. Buenos Aires: Solar, 1991.

PAPAZIAN, Alexis. Pulmarí: ¿cartografías para quién?. In: CONGRESO ARGENTINO DE ANTROPOLOGÍA SOCIAL, 9., 2008, Posadas. Actas... Posadas: Universidad Nacional de Misiones, 2008. p. 1-20.

RAPPAPORT, J oanne. Geography and historical understanding in indigenous Colombia. In: LAYTON, Robert (Ed.) Who needs the past? indigenous values and archaeology. Londres: Unwin Hyman, 1989. p. 84-94.

RUMSEY, Alan. Tracks, traces, and links to land in aboriginal Australia, New Guinea, and beyond. In: RUMSEY, Alan; WEINER, J ames (Ed.). Emplaced mith: space, narrative, and knowledge in aboriginal Australia and Papua New Guinea. Honolulu: University of Hawaii Press, 2001. p. 19-42.

SANTOS GRANERO, Fernando. Writing history into the landscape: space, myth, and ritual in contemporary Amazonia. American Ethnologist, Washington, v. 25, n. 2, p. 128-148, 1998.

STEWART, Pamela J .; STRATHERN, Andrew. Origins vesus creative powers: the interplay of movement and fixity. In: RUMSEY, Alan; WEINER, J ames (Ed.). Emplaced mith: space, narrative, and knowledge in aboriginal Australia and Papua New Guinea. Honolulu: University of Hawaii Press, 2001. p. 79-98. 
Ana Ramos y Walter Delrio

Mapas y narrativas de desplazamiento: memorias mapuche-tehuelche ... 